\title{
Necessidade de Novos Paradigmas Ambientais Implicações e Contribuição Guarani
}

\section{Clovis Antonio Brighenti *}

Resumo: $O$ debate acerca da questão ambiental carece de novos paradigmas para atingir um maior equilíbrio da totalidade complexa físico-biológica-antropológica. A prática moderna de criação de algumas Unidades de Conservação não dará conta de sustentar todo o ambiente complexo. A concentração de terra, renda e o consumismo são indícios de um ecossistema ameaçado. O povo indígena Guarani, tradicionalmente ocupante da Mata Atlântica, enfrenta conflitos com ambientalistas e são acusados de invasores de áreas preservadas. Reivindicam a devolução de seus tekoha, local onde podem viver seu modo de ser. Além de justa e legal reivindicação, os Guarani têm muito a contribuir para a formulação dos novos paradigmas. Mantêm uma relação de profundo respeito com o meio ambiente e suas práticas econômicas privilegiam a distribuição recíproca dos bens, sem acumulação.

Palavras-chave: Guarani, Território, Meio Ambiente, Mata Atlântica, Unidades de Conservação.

Abstract: The debate about the environmental question lacks new models to reach a greater balance of the total complexity physical-biological-anthropological. The modern practice of the creation of some Conservation Units won't be able to sustain this complex environment. The concentration of land, income and buying power are indicators of a threatened eco-system. The Guarani Indians traditionally occupants of the Atlantic Forest confront conflicts with environmentalists and are accused of being invaders of preserved lands. They vindicate the devolution of their Tekoha, place where they can live their way of life. Besides fair and lawful vindication, the Guarani have a lot to contribute to the formulation of new models. They maintain a relationship of profound respect of the environment and their economic practice privileges the reciprocal distribution of theirs goods, without accumulation.

Keywords: Guarani, Territory, Environment, Atlantic Forest, Units of Conservation

\footnotetext{
* Membro do Conselho Indigenista Missionário - Cimi e Mestre em Integração da América Latina pelo Programa de Pós Graduação em Integração da América Latina. E-mail: clovisbrighenti@zipmail.com.br, cheiru@terra.com.br. Recebido em 23/02/05 e aceito em 09/05/05
} 


\section{Introdução}

A preocupação com a questão ambiental no Brasil fez surtir avanços significativos nos últimos anos, tendo na legislação brasileira do meio ambiente uma referência importante para garantir e dar sustentação as ações da sociedade na conscientização, defesa e preservação do ecossistema. Segundo Rocco (2002, p. 16) um dos avanços legais foi a conceituação do direito ambiental, que traz uma singularidade por ser um direito coletivo, difuso, sem determinação de seus destinatários, ou seja, "todos e qualquer um são legítimos para pleitear sua defesa”. Todavia, Diegues (1996, p. 118) tece críticas ao SNUC - Sistema Nacional de Unidades de Conservação, por constatar que os avanços refletem uma visão extremamente conservadora da conservação ambiental no Brasil, e que está muito aquém dos debates mundiais. Segundo esse pesquisador, o "SNUC vê essas unidades como verdadeiras ilhas interligadas entre si para constituir o sistema. Não há nenhuma consideração substancial de como esse sistema contribui para a conservação e o desenvolvimento sustentado do país como um todo... Em suma, o SNUC é um "sistema fechado", isolado da realidade e do espaço total brasileiro que tem sido amplamente degradado e "mal desenvolvido" há décadas". No entanto, constatamos que nem mesmo os avanços conquistados na legislação têm se traduzido em açóes de defesa do meio ambiente. As inúmeras denúncias na imprensa e a percepção cotidiana de que o meio ambiente continua sendo degradado, são sinais de desregulação entre a legislação e a política ambiental. Partiremos do pressuposto de que a desregulação não se localiza na ausência de legislação, ações preventivas ou omissóes, mas substantivamente na subserviência das decisóes políticas aos interesses econômicos. A concessão de licença ambiental para atividades potencialmente poluidoras e socialmente concentradoras de recursos naturais e renda, demonstra uma preocupação mais voltada para o princípio econômico do que propriamente para o equilíbrio da totalidade complexa físico-biológico-antropológico.

A necessidade de manter preservado alguns exemplares da biota, além de outros fatores, tem impulsionado a criação de espaços preservados. Conforme assinala Diegues (1996), muitas vezes esses espaços preservados se sobrepóem a direitos e interesses de comunidades tradicionais e comunidades indígenas. É nesse quadro que constatamos, nos últimos anos, um 
agravamento dos conflitos estabelecidos entre a necessidade de preservação e o direito e demandas das populaçóes indígenas em todas as regióes do Brasil. São conflitos das mais diversas ordens, que vão do debate teórico, pressupostos e concepçóes a interferências diretas no sentido de não permitir que essas populaçóes reivindiquem a demarcação de suas terras quando estas estiverem sobrepostas por Unidades de Conservação. São muitas açóes na Justiça, nas várias esferas, bem como intervençóes de ordem política junto ao Ministério da Justiça e Funai para reverter procedimentos de identificaçóes e demarcações de terras indígenas. Essas açóes contrárias ao reconhecimento do direito indígena, quando este se relaciona com as Unidades de Conservação, partem tanto de entidades da sociedade civil, através das Organizaçóes Não Governamentais, bem como de órgáos ambientais municipais, estaduais e federal.

O presente artigo objetiva problematizar essa questão buscando identificar historicamente a relaçáo que os povos indígenas estabelecem com o meio ambiente identificando as principais tensóes e apontando possibilidade de compatibilização. Para isso será necessário uma ruptura com o mito de que alguns nichos ecologicamente preservados darão contas de dar sustentabilidade ao planeta. Faremos um exercício de desconstruir algumas teorias sobre o meio ambiente, para interiorizar as visóes e práticas indígenas. Será necessário também uma 'ampliação do horizonte' para compreender o ambiente em sua amplitude, onde os elementos bióticos e antrópicos voltem a ser integrados. Falamos em retorno, porque compreendemos que a grande questão ambiental surgiu com o advento da sociedade moderna, especialmente com a industrialização, a acumulação econômica e as grandes concentraçóes em centros urbanos, reduzindo o meio ambiente a espécies vegetais e animais. Se surgiu a preocupação é porque o ambiente está sendo destruído de maneira avassaladora. As Unidades de Conservação, por outro lado, náo questionam o modelo, apenas buscam contemplar um mínimo de espaço a ser preservado, muitas vezes com recursos dos próprios setores destruidores, o que gera profunda contradição e incoerência ${ }^{1}$.

\footnotetext{
${ }^{1}$ Em Santa Catarina, no ano 2004, a Fundação Estadual do Meio Ambiente - FATMA concedeu o Prêmio Fritz Müller de Conservação Ambiental a uma empresa de reflorestamento, por manter 41,5 ha de mata atlântica preservados (Reserva Particular do Patrimônio Natural) de excelente paisagem cênica. O local transformou-se num espaço de turismo. No entanto, essa mesma empresa ocupa 40,5 mil hectares de florestas exóticas de Pinus destinados à indústria.
} 
Buscaremos aprofundar a compreensão a partir das perspectivas do povo indígena Guarani ${ }^{2}$, mais especificamente dos subgrupos lingüísticas Mbya e Xiripa, já que são estes que ocupam uma ampla parcela da região do Cone Sul, em partes do Brasil, Argentina, Paraguai e Uruguai. Mantêm uma relação profunda com a Mata Atlântica, local privilegiado para os tekohasl espaços sagrados de convivência.

Também faremos um enfoque na relação das comunidades indígenas com as Unidades de Conservação por considerarmos que são essas as principais dinamizadoras das tensóes entre os Guarani e órgãos ambientais. Buscaremos, num primeiro momento, verificar alguns aspectos históricos, territoriais e culturais Guarani para, num segundo momento, compreender sua relação com o meio ambiente e posteriormente esboçar um contraponto com o modelo de conservação em curso. Nossa orientação está em entender o relacionamento Guarani com o meio ambiente e elaborar uma interface com a visão moderna de meio ambiente, consubstanciando as possibilidades de abertura a um diálogo, com vistas a contribuir no debate sobre a garantia das terras a esse povo indígena, condição fundamental para sua sobrevivência cultural.

Os Guarani têm muito a contribuir não apenas com novos paradigmas para o modelo ambiental, mas com dizeres e experimentos de possibilidades concretas para um novo relacionamento da sociedade com o ambiente. Entendemos que essa concepção específica Guarani para compreender a relação homem natureza deve ser o centro dos debates.

\section{Espaço transfigurado. A fragmentação do território guarani}

O território de ocupação tradicional Guarani Mbya e Xiripa sobrepóemse quase que exclusivamente às regióes com cobertura vegetal da Mata Atlântica ${ }^{3}$ ou Selvas Paranaense e subtropicais, como é considerada essa mata na Argentina e Paraguai.

\footnotetext{
${ }^{2}$ Quanto à grafia dos nomes indígenas, seguimos as normas da Associação Brasileira de Antropologia (ABA), que propõe que o nome de grupos inicie-se por maiúsculo e que seja sem flexão de gênero e número. Sendo adjetivo, terá flexão como em português.

${ }^{3}$ Não há consenso sobre a denominação dessa floresta. Para alguns estudiosos a Mata Atlântica refere-se tão somente às florestas densas ao longo do litoral. Mas no Brasil, o Decreto 750/93 definiu a abrangência da incidência dessa mata, visando consolidar medidas de proteção.
} 


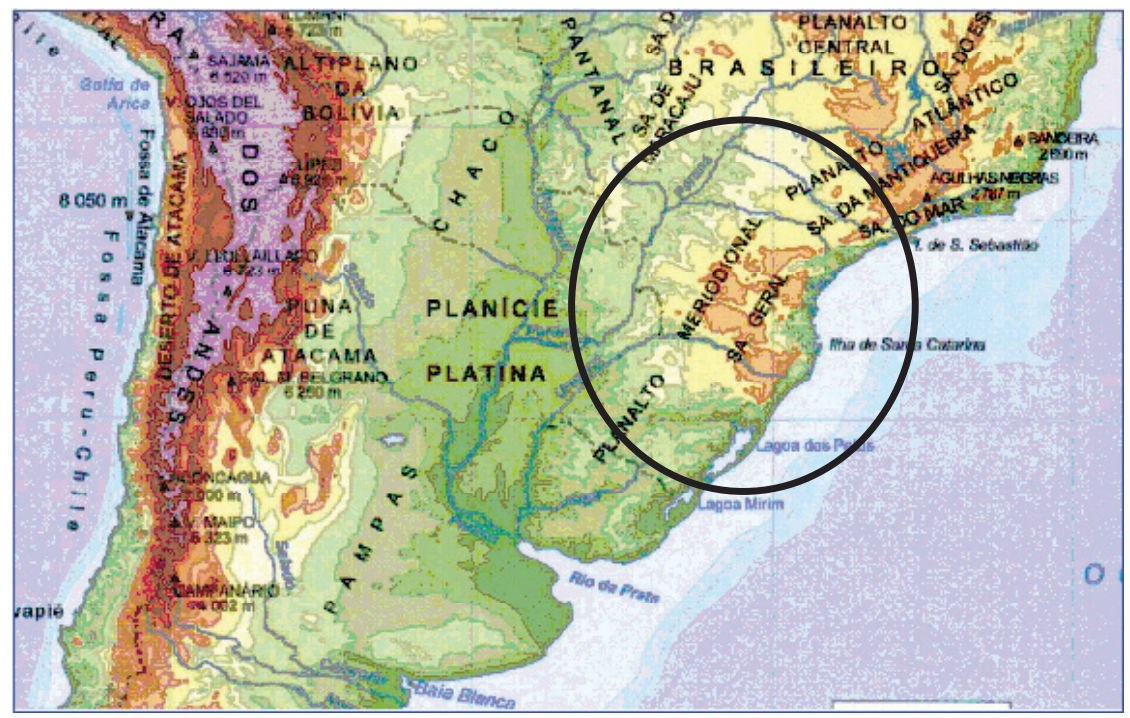

Figura 1 - Cone Sul da América - Destaque circular ao território de ocupação Guarani ${ }^{4}$

A etnografia que trata do território ocupado pelos Guarani à época da conquista é bastante ampla e homogênea, não havendo contradiçóes comprometedoras entre os diferentes pesquisadores. "A maioria das populaçóes indígenas encontradas pelos desbravadores quinhentistas em terras da bacia platina falava dialetos do idioma Guarani, estreitamente afim ao linguajar das chamadas tribos Tupi, que dominavam quase todo o litoral brasileiro e grandes extensóes do interior" (SCHADEN, 1974, p. 01). Essas informaçóes históricas não fazem recorte entre os diferentes subgrupos lingüísticos. Na tentativa de unificação de pronúncia, Schaden organizou, nos anos 50, uma nova classificação dos subgrupos lingüísticos Guarani encontrados no Brasil e que serviu também para classificar os grupos Guarani que vivem no leste do Paraguai e na província de Misiones, na Argentina: Mbyá, Kaiowá (ou Paí no Paraguai) e Nhandeva (ou Xiripá no Paraguai). Essa classificação serviu de base para estudos posteriores, e ainda não foi convincentemente questionada pelos pesquisadores do tema. A partir de dados históricos é possível reconstituir um território básico ocupado por esse povo no momento da conquista. Para Melià (1989, p. 294), a cerca de

\footnotetext{
${ }^{4}$ Referência a partir dos dados históricos e da ocupação contemporânea.
} 
2.000 anos "esses grupos que conhecemos como Guarani passaram a ocupar as selvas subtropicais do Alto Paraná, do Paraguai e do Uruguai Médio”.

Segundo esse mesmo pesquisador, não se tratava de grupos nômades, que viviam exclusivamente da caça e coleta, mas eram excelentes agricultores, que mantinham um estreito relacionamento com as terras de selva, cultivando com a prática da coivara. Também eram hábeis ceramistas, que fabricavam todos os utensílios necessários a servir e preparar os alimentos, e conclui: "Como colonos dinâmicos, os Guarani continuarão sua expansão migratória até os tempos da invasão européia no Rio da Prata (na década de 1520) e ainda em plenos tempos históricos até nossos dias".

Essa população não ocupava uniformemente todas as regióes. Para Saguier (1980, p. 18) havia uma maior concentração Guarani num núcleo central na mesopotâmia dos rios Paraná e Paraguai e a partir desse núcleo estendiamse por um território mais amplo. "Pode-se dizer que os Guarani habitavam a atual região oriental do Paraguai, o estado do Mato Grosso e partes da costa Atlântica, no Brasil, e a província de Misiones na Argentina, com algumas fixaçôes em território boliviano pelo noroeste e Uruguai pelo sudeste”. Já Hélène Clastres (1978, p. 8) não identifica um núcleo populacional central para o Guarani, mas, pela sua descrição, percebe-se que essa população ocupava uma ampla região no Cone Sul americano, em praticamente todo o litoral, desde Cananéia (SP) ao Rio Grande do Sul, penetravam pelo interior, tendo como limite oeste o Rio Paraguai, ocupavam as duas margens do Rio Paraná até a sua confluência com o Rio Paraguai. Ao norte, esse território limitava-se com o Rio Tietê.

Embora se visualize um amplo espaço ocupado, os pesquisadores alertam que não se tratava de um território contínuo e densamente povoado. Dentro dessa extensão geográfica, os Guarani não constituíam uma população regionalmente compacta e homogênea. Preferiam os locais com florestas da Mata Atlântica, tropicais e subtropicais, no litoral e entre os principais rios formadores da bacia do Paraná/Paraguai.

Neste amplo território, os Guarani formavam aquilo que os missionários espanhóis chamaram de conjuntos territoriais ou provincias. Esses conjuntos territoriais mantinham estreita comunicação, ligavam-se por diversos caminhos amplamente povoados, destacando-se na historiografia o Peabiru. 
Foram classificadas 14 conjuntos territoriais e cada qual com diversas nucleações.

Se para os espanhóis esses conjuntos territoriais eram denominados provincias, para os Guarani, no entanto, eram denominados guára (guára é o conjunto de diversos tekoha/aldeias que por sua vez são formados por várias te’ýi/família extensa). Dada a unidade lingüística dos diferentes dialetos que compunham os vários guára, além da estreita relação na organização sóciopolítica e nas manifestaçóes culturais, receberam o nome genérico Guarani, que se perpetua até os dias atuais.

De uma população estimada em 2 milhóes de habitantes (MELIÀ, 1989, p. 295) a grande maioria foi escravizada pelos Vicentistas e Bandeirantes e morta em confrontos com invasores europeus e epidemias. Uma outra parcela significativa dessa populaçáo foi agrupada nas reduçóes dos Padres Jesuítas e Franciscanos. Locais como a costa catarinense e a região do Tape no RS foram quase que totalmente despovoadas dessa população até o século XVII. Porém uma parcela significativa dessa população permaneceu livre, ocupando e deslocando-se no território mais ao Leste, fronteira Brasileira com o Paraguai - foram denominados Monteses, Káayguá, Caaiguás naquele país. Clastres (1978, p. 30) escreve sobre esses grupos de Guarani náo submetidos, que escaparam dos "jesuítas e dos colonos e conservavam a sua autonomia, porque se estabeleceram num território que durante muito tempo permaneceu inacessível: daí a denominação de caaiguás ou cainguás (= gente da floresta) que lhe foi atribuída (...). Descendem dos cainguás, provavelmente, os três grupos tribais - mbiá, chiripa e paim - que vivem no Paraguai até hoje".

Esta tese é compartilhada por Ladeira (1992, p. 22) ao afirmar que "os Mbya descendem dos grupos que náo se submeteram aos encomenderos espanhóis e tampouco às missóes jesuíticas, refugiando-se nos montes nas matas subtropicais da região do Guairá paraguaio e dos sete povos”. Eram grupos sobreviventes nas selvas e mal conhecidos, pouco visitados, já não despertavam maiores interesses econômicos dos países da região.

Essa população Guarani ficou concentrada na região onde a mata era mais abundante, provendo seu sustento e também mantendo-se afastados, mas não livres, das inúmeras intervençôes de exploradores e missionários. A regiáo compreendida entre o leste paraguaio, a província de Misiones, o oeste dos estados sulistas brasileiros e toda a regiáo sul do MS eram os locais 
privilegiados para manterem-se livres. "Persiste uma questão que a etnohistória não respondeu, sobre a presença da população Guarani não reduzida fora da regiấo leste paraguaia. Teriam existido e onde estariam localizados, uma vez que dos relatos só temos informaçóes de vazios populacionais Guarani, como o Guairá, Tape e os Carijó do litoral. Acreditamos que não desapareceram totalmente" (BRIGHENTI, 2001, p. 100). Certamente se readequaram ao espaço então disponível e reconstruíram socialmente e culturalmente novas maneiras de sobrevivência. A busca incessante de novos espaços ambientalmente adequados, capazes de garantir a sobrevivência física e cultural, fez desses Guarani um povo migrante, sempre buscando um novo local onde possam viver a 'plenitude'.

Um dos traços mais característicos dos Guarani são as migraçóes e os deslocamentos sempre em busca da terra sem mal. "Como veremos, a busca da "terra sem mal" e de uma "terra nova" estrutura marcantemente seu pensamento e suas vivências; a "terra sem mal” é a síntese histórica e prática de uma economia vivida profeticamente e de uma profecia realista, com os pés no chão. Animicamente o Guarani é um povo em êxodo, embora não desenraizado, pois a terra que procura é a que lhe servirá de base ecológica, amanhã como em tempos passados” (MELIÀ, 1989, p. 294).

A terra sem mal Guarani, portanto, está pautada na possibilidade do viver a plenitude no espaço terreno. É a possibilidade de continuar vivendo os valores culturais, sociais, econômicos e religiosos para serem verdadeiramente os autênticos. Essa possibilidade se concretiza somente quando o meio oferecer as condiçóes básicas para a sobrevivência, que implica fundamentalmente o ambiente preservado.

Essas migraçóes e busca dos locais ambientalmente preservados se dá dentro do seu território tradicional. Esse território, segundo Ladeira (1992, p. 57), é parte do Paraguai, da Argentina, do Uruguai e do Brasil. "As aldeias e os movimentos atuais vêm comprovar que, embora a disponibilidade de terras lhes seja irrisória e cada vez seu espaço no seu mundo esteja diminuindo, os Guarani continuam fiéis na identificação de seu território, elegendo seus lugares dentro dos mesmos limites geográficos observados pelos cronistas durante a conquista". Nesse aspecto é importante perceber que as migraçóes atuais conectam os Guarani com o sentido próprio de sua existência e ao território histórico no Séc. XVI. Porém, a ocupação atual ocorre de maneira fragmentada, descontínua, mas interligada por relaçóes de parentesco, por necessidade de intercâmbio de sementes e mudas de plantas cultivadas 
tradicionalmente, pela manutenção e vivência dos valores religiosos e por redes de reciprocidades. Seu território está circunscrito numa regiảo definida em termos geográficos e ecológicos preferencialmente na regiáo de formação florística da Mata Atlântica. Os Guarani interpretam como de sua herança sagrada as terras com matas. "Nossos velhos sempre falaram que onde tem um lugar com mata, com água limpa, com taquara e outros tipos de plantas, como animaizinhos, onde é possível plantar milho, mandioca, batata, feijão é lugar do Guarani. Isso quer dizer que todos os lugares que é possível fazer um tekoha, lugar autêntico, então esse lugar é do Guarani, são poucos lugares que ainda restam pro Guarani. Nos lugares que tem cidade, indústria, poluição, então esse lugar fica pro branco." (Comunidades Guarani do Litoral Catarinense, 2004, p. 09).

O olhar Guarani sobre o não indígena, no aspecto ambiental, identifica-o com a desordem, o profano e o desleixo com o ambiente. Já os próprios se auto-identificam como "autênticos", suas atitudes são no sentido da coerência com o sagrado, mantém consciência de que os espaços minimamente preservados estão sendo destruídos, restam poucos ${ }^{5}$. Continuam insistindo que esse pouco deve ser devolvido ao povo Guarani e esse processo ocorre pela revelação. Legalmente, conforme veremos adiante, a relação que mantém com o espaço revelado/tradicional se sobrepóe a qualquer forma de titulaçáo ou reivindicação da terra pelos náo-indígenas, sendo indiferente se a terra com mata é titulada, é de particulares ou se está sobreposta por Unidade de Conservação.

A identificação e regularização das terras ${ }^{6}$ constitui-se num desafio à sobrevivência, já que a posse ocorre em fraçóes mínimas das terras reivindicadas. Os locais já regularizados são em tamanho insignificantes, o que não possibilita sua sobrevivência. Num estudo comparativo que desenvolvemos em $2001^{7}$, sobre esse aspecto, entre o Estado de SC e a Província de Misiones (AR), constatamos que apenas $16 \%$ das terras regularizadas aos Guarani ${ }^{8}$ tinham tamanho superior a 1.000 ha e $30 \%$ delas estavam com tamanho abaixo de 100 ha, ou seja, sáo de tamanhos insignificantes para atender às necessidades culturais dessas comunidades.

\footnotetext{
${ }^{5}$ Segundo o Instituto Sócio-Ambiental, a Mata Atlântica ocupa menos de 8\% do território original (ISA,1999).

${ }^{6}$ Sobre a identificação, delimitação e demarcação de Terra Indígena, a Funai segue o disposto no Art. 231 da CF, o Decreto 1775/96, a Portaria 14 do MJ e a lei 6001/73, conhecida como Estatuto do Índio.

${ }^{7}$ Dissertação de mestrado apresentada como requisito parcial para obtenção do título de Mestre pelo PROLAM/USP.

${ }^{8}$ - No trabalho consideramos terras regularizadas as tituladas em nome das comunidades Guarani, no caso da Argentina, e Demarcadas fisicamente, no caso do Brasil.
} 


\section{O saber tradicional - o olhar guarani sobre o ambiente}

O tekoha ${ }^{9}$, para o Guarani, talvez seja a síntese da concepção e da relação que esse povo mantém com o meio ambiente. No plano físico poderíamos dizer que o tekoha é a aldeia, é o lugar onde a comunidade Guarani encontra os meios necessários para sua sobrevivência. É a conjugação dos vários espaços que se entrecruzam: o espaço da mata preservada onde praticam a caça ritual; espaço da coleta de ervas medicinais e material para confeccionar artesanatos e construir suas casas; é o local onde praticam a agricultura; é também um espaço sócio político, onde constroem suas casas de moradias, a casa cerimonial/ $O p y$, o pátio das festas, das reuniôes e do lazer. Não é possível conceber o tekoha sem a composição dos espaços, ou apenas um dos espaços; nesse caso, não poderão viver a plenitude e assim se quebra a relação que mantém com o meio, produzindo o desequilíbrio.

Vejamos o que nos falou Werá Tupã a respeito do tekoha ${ }^{10}$ :

É o lugar onde se vive a vida. Está ligado ao lugar, à comunidade, à pessoa. Um lugar que tenha água abundante, mato pra tirar as coisas pra sobreviver, como o mel, o palmito, mundé, artesanato. Lugar onde dá pra fazer as casas, roças, plantas, as danças, onde dá pra fazer um trabalho de cidadania com os jovens, ter educação. Onde faltam essas coisas não é um tekoha, é um "tekohazinho", tekoha precário, como um bairro pobre da cidade, que não tem muito infra-estrutura.

Além de processar todo o conjunto de condições necessárias à manutenção das necessidades físicas, a terra identificada com o tekoha, produz os meios fundamentais para a existência do modo de ser Guarani. Melià (1989, p. 336) compreende que a "terra concebida como tekohá é antes de tudo um espaço sócio político. O tekohá significa e produz ao mesmo tempo relaçóes econômicas, relaçóes sociais e organização política e religiosa, essencial para a vida Guarani... Ainda que pareça um paralogismo, é necessário admitir (...) que sem tekohá não existe tekó”.

Nesse aspecto o tekoha possibilita não apenas a sobrevivência, mas também a recriação permanente de sua identidade, suas relaçôes sociais,

\footnotetext{
${ }^{9}$ TEKOHA - tekó é o modo de ser, o sistema, a cultura, a lei e os costumes; o tekoha é o lugar e o meio em que se dão as condições de possibilidade do modo de ser Guarani.

${ }^{10}$ Depoimento ao autor em outubro de 1999.
} 
sua relação com o sagrado e seu modo de ser. É um projeto integrador, que privilegia a sustentação harmoniosa e equilibrada entre o humano, o espiritual e a natureza. Nesta concepção integradora não é possível conviver com a apropriação individual dos recursos naturais, assim como não se pode conceber a terra como propriedade particular. A própria aceitação das terras demarcadas, mesmo sabendo que essa prática, no momento atual, é a forma mais adequada para que possam recuperar um pouco das terras subtraídas no passado, necessitou uma reinterpretação e uma readequação na formulação dos saberes culturais. Muitos velhos, especialmente os que têm a função de líderes espirituais, continuam ignorando qualquer forma de delimitaçáo de terras.

Para os Guarani o ser humano é parte do todo, nem inferior nem superior aos demais seres que compóem a natureza. Assim sendo devem manter-se em permanente harmonia com ela e em profundo estado de respeito, utilizandoa de maneira equilibrada, de modo que a sua sobrevivência náo signifique a destruição da natureza e que o humano não padeça de necessidades tendo recursos naturais disponíveis. Sua interpretação cosmológica é no sentido de atribuir aos animais e plantas predicados e códigos morais humanitários. O equilíbrio significa também a relaçáo de igualdade, porque entendem que todos são criaturas de um mesmo Deus - Nanderu Tenonde/Nosso Criador Primeiro -, pessoas morais e sociais, embora cada qual seja regido por um espírito próprio. Para Melià a terra Guarani vive com os Guarani que nela vivem. Essa interpretação é expressa na prática de pedir licença à divindade criadora para efetuar a caça, para fazer derrubada para o plantio ou para a extraçáo de produtos nativos, invocando o profundo respeito pelo ambiente. Porém, Noelli (1993, p. 112) afirma que a relação dos Guarani com o ambiente não é de passividade, mas nutrem um profundo conhecimento dos meios bióticos e abióticos, possibilitando um manejo sustentável das plantas.

A mata cumpre uma função importante no equilibro da natureza. Detém um conhecimento muito apurado sobre a variedade de plantas e suas funçóes, que são insubstituíveis. Algumas árvores jamais poderão ser derrubadas, a não ser para rituais ou para cumprir determinada função ímpar. Dentre elas destacamos o Pindó/Palmeira, planta cultivada pelos Xamãs por ser o sustentáculo do mundo; O Yvyra Néery/Cedro, planta sagrada utilizada em rituais religiosos, como no batismo, em banhos e chás para purificar o corpo 
e o espírito. Há também plantas que não devem ser utilizadas para fins espirituais por serem representantes do mal.

A agricultura praticada pelos Guarani, além de manter um extensa lista de variedade de plantas e cultivares, baseia-se numa técnica itinerante, que consiste na rotatividade do uso do solo. Como afirma Fogel (1998, p. 44) "depois de 3 a 4 anos de uso continuado da mesma lavoura - ao baixar a produção - deixam o solo descansar até que se retome a fertilidade: é uma das formas de manter o equilíbrio ecológico. Não é permitido derrubar a mata se não for utilizado para o plantio". Importante observar que os Guarani praticam um intenso manejo ambiental, pois com o tempo de descanso da terra e sua regeneração e ao longo das trilhas nas matas secundárias, crescem as plantas utilizadas na coleta, atraindo animais e ampliando a fomentando a multiplicidade de espécies.

Em 1976 o Manifesto Ecológico Brasileiro já destacava a relação e a importante contribuição indígena na manutenção da biodiversidade, ao declarar: "O índio, muitos milênios antes da chegada do homem branco, já havia alcançado situaçóes de equilíbrio estável em seu ambiente. No mar da natureza intacta, as derrubadas do índio, pequenas e grandes distâncias umas das outras, constituíam até vantagens ecológicas, pois acrescentavam diversidade ecológica ao sistema. Nestas clareiras vingavam os organismos pioneiros, as plantas e os animais das comunidades de recuperaçáo, que são os tecidos cicatrizantes dos ecossistemas" (DIEGUES, 1996, p. 150). Estudos recentes apontam que essas práticas tradicionais de agricultura itinerante estão contribuindo para a manutenção e o aumento da diversidade biológica das florestas tropicais

"Além do notável conhecimento das plantas e animais chama atenção a forma como os Mbyá Guarani valorizam os recursos naturais: essa valorização cultural os leva ao aproveitamento de grande parte do potencial produtivo do ecossistema, por mais frágil que ele seja” (FOGEL, 1998, p. 37).

O conhecimento, o relacionamento e o domínio da formação florística da Mata Atlântica concedem aos Guarani total autonomia de sobrevivência em equilíbrio com o meio ambiente. Seu universo cultural, econômico e mítico está intimamente relacionado com o ambiente, não seria possível sua sobrevivência e a sobrevivência do meio ambiente se não praticassem uma economia de reciprocidade e não acumulativa. Portanto, a existência 
do tekoha, lugar do tekó, da maneira tradicional de ser, ocorre a partir da vivência profunda do Guarani com o meio ambiente.

\section{O ambientalismo como negação do tradicional.}

No território Guarani ${ }^{11}$ identificamos pelo menos 25 conflitos resultantes da disputa entre interesses das comunidades Guarani e Unidades de Conservação já implantadas ou em vias de implantação, sejam de âmbito federal ou estadual.

${ }^{11}$ Consideramos território Guarani porções do território brasileiro, argentino e uruguaio. No caso das unidades de conservação em sobreposição as terras Guarani, não encontramos informações do Paraguai. 
Tabela 1 - Terras indígenas com sobreposição de unidades de conservaçáo

\begin{tabular}{|c|c|c|c|c|}
\hline & Terra Indígena & Unidade de Conservaçáo & UF & PAÍS \\
\hline 01 & Morro dos Cavalos & \multirow{3}{*}{ Parque Estadual Serra do Tabuleiro } & \multirow{3}{*}{ SC } & \multirow{3}{*}{ BRASIL } \\
\hline 02 & Cambirela & & & \\
\hline 03 & Massiambu & & & \\
\hline 04 & Ita Guasu & $\begin{array}{c}\text { Área de Proteção Ambiental Serra } \\
\text { Dona Francisca }\end{array}$ & SC & BRASIL \\
\hline 05 & Itapuã & Parque Estadual do Itapuã & RS & BRASIL \\
\hline 06 & Morro das Pacas & Parque Nacional do Superagui & PR & BRASIL \\
\hline 07 & Ilha do Cardoso & Parque Estadual Ilha do Cardoso & SP & BRASIL \\
\hline 08 & Peguaoty & Parque Estadual Intervales & SP & BRASIL \\
\hline 09 & Paraíso & Estação Ecológica Juréia & SP & BRASIL \\
\hline 10 & Aguapeú & \multirow{4}{*}{ Parque Estadual da Serra do Mar } & \multirow{4}{*}{ SP } & \multirow{4}{*}{ BRASIL } \\
\hline 11 & Rio Branco & & & \\
\hline 12 & Rio Silveira & & & \\
\hline 13 & Boa Vista & & & \\
\hline 14 & Arapongas & Parque Nacional da Serra da Bocaina & $\mathrm{RJ}$ & BRASIL \\
\hline 15 & Nhamandu & \multirow{4}{*}{ Parque Provincial Kunapiru } & \multirow{4}{*}{ MI } & \multirow{4}{*}{ Argentina } \\
\hline 16 & Yyovy, & & & \\
\hline 17 & Ponte Queimada & & & \\
\hline 18 & Yakã Porã. & & & \\
\hline 19 & Itachi; & \multirow{7}{*}{ Reserva da Biosfera Jabuti } & \multirow{7}{*}{ MI } & \multirow{7}{*}{ Argentina } \\
\hline 20 & Jejy & & & \\
\hline 21 & Pindopoty & & & \\
\hline 22 & Yakã Pa’u; & & & \\
\hline 23 & Tekoha Yma; & & & \\
\hline 24 & Kapi’i yvaté, & & & \\
\hline 25 & Caramelito & & & \\
\hline
\end{tabular}

FONTE: Dados do Cimi Regional Sul, Endepa e CTI-SP

Os conflitos são externados de várias maneiras: em muitas situações a remoção das comunidades indígenas foi efetivada sem o consentimento da mesma; alguns casos o embate se processa através de açóes judiciais; há outros 
casos em que as organizaçôes ambientalistas tentam impedir que o Órgão Indigenista Federal, responsável pela demarcação das Terras Indígenas, exerça sua função através da pressão política; mas o mais comum são as intimidações e restriçóes quando ao uso de recursos naturais na tentativa de fazer com que a própria comunidade indígena abandone "espontaneamente" as Unidades de Conservação. Nos casos em que há maior tolerância busca-se monitorar e controlar as comunidades Guarani para que utilizem de maneira restrita os recursos ambientais das UC, como taquara, cipó, madeira para construção, derrubadas para plantio e outros recursos para confeccionar artesanatos. Há casos também em que o órgão ambiental oferece regularmente alimentos para a comunidade Guarani a fim que a mesma náo extraia recursos naturais e não necessite fazer lavouras.

Esses conflitos são resultantes da concepção específica da relação homem/natureza, própria das sociedades modernas, que concebem o desenvolvimento econômico como total apropriação e dominação da natureza e concomitantemente mantêm um senso de superioridade com relação a ela e vêem o meio ambiente de maneira utilitarista. Essa concepção, segundo Diegues (1999, p. 9), "parte do princípio de que toda relação entre sociedade e natureza é degradadora e destruidora do mundo natural e selvagem". Para esse mesmo pesquisador, o movimento naturalista de proteção da natureza do século passado defendia que a única maneira de proteger a natureza era afastá-la do homem. A criação de parques e reservas continua sendo apresentada como estratégia principal para conservação da natureza. Embora inicialmente a criação de parques tivesse como finalidade a "recreação e enlevo das populaçóes urbanas, educação ambiente e pesquisa. A manutenção da biodiversidade apareceu como objetivo da conservaçáo como resultado rápido do desaparecimento de espécies e ecossistemas, particularmente a partir da década de 60" (DIEGUES, 1996, p. 149). Nessas situaçóes o Guarani aparece como um impedimento à preservação e não como somatória de contribuições à preservação do ambiente indiviso.

Portanto temos pela frente um conflito de visóes, práticas e saberes distintos relacionados ao meio ambiente. Um equacionamento da questáo implica na alteração profunda dos princípios norteadores do desequilíbrio ambiental. 


\section{Direito à diferença}

Os direitos indígenas nas Constituições Nacionais dos países que se sobrepóem ao território Guarani tiveram avanços bastante notáveis nas últimas décadas ${ }^{12}$. A Constituição do Paraguai de 1992, em seu Art. 62, passou a reconhecer a existência de Povos Indígenas, aí definidos como grupos de cultura anteriores à formação e organização do Estado paraguaio. O alcance desse texto é inimaginável, pois ele inverte a própria formação histórica do Estado, ao reconhecer que antes dele já existiam povos indígenas.

A reforma Constitucional Argentina de 1995 também trouxe avanços significativos para o reconhecimento dessa população indígena. A partir da reforma (Alterou o Art. 75, relativo às atribuições do Congresso Nacional) ficou estabelecida nova pauta de relacionamento entre o Estado e os Povos Indígenas, especialmente no reconhecimento da existência desses povos e o respeito à sua identidade: ficou reconhecido a "preexistência étnica e cultural dos povos indigenas argentinos"...

No Brasil, a Constituição Federal de 1988 também avançou significativamente no reconhecimento dos indígenas enquanto portadores de saberes, culturas e formas próprias de organização social. A partir desse marco, o Estado brasileiro passa a reconhecer e respeitar os indígenas em suas formas próprias. Esse novo ordenamento jurídico eliminou por completo a tradição histórica brasileira da "integração indígena". A CF de 1988 foi a primeira Constituição brasileira a dedicar capítulos específicos ao tratamento dirigido aos indígenas (Cap. VIII) e ao Meio Ambiente (Cap. VI).

Embora ainda não exista uma legislação unificada dos diferentes países para contemplar as especificidades do povo Guarani, notamos que houve avanços significativos em cada país ${ }^{13}$. No momento que os Estados Nacionais passaram a reconhecer aos povos indígenas as formas próprias da organização social, da cultura, das crenças e tradições, devem respeitar as práticas cotidianas das relaçóes que mantêm com o meio ambiente, fruto da vivência cultural. Dessa forma o povo Guarani goza de amparo legal para continuar exercitando suas práticas culturais e tradicionais de migração e busca de novas terras.

\footnotetext{
${ }^{12}$ Estamos nos referindo ao Brasil, Argentina e Paraguai. No caso do Uruguai, que também conta com uma pequena população Mbyá, o indígena não é tratado na Constituição Nacional.

${ }^{13}$ Argentina (2000), Brasil (2004) e Paraguai (1993) são signatários da Convenção 169 da Organização Internacional do Trabalho, sobre povos indígenas e tribais em países independentes.
} 
Contudo, o êxito obtido no enfoque legal está distante da prática. Um efeito dessa equação emerge quando se busca através de práticas coercitivas e ou impeditivas restringir o uso, pelos Guarani, das áreas eleitas por eles quando estas são consideradas Unidades de Conservação, desta forma está sendo colocado em questionamento o direito tradicional desse povo indígena, direto esse assegurado no $₫ 1^{\circ}$ do Art. 231 da Constituição Federal. $\mathrm{Na}$ interpretação de Guimarães (2000, p. 549) "as terras tradicionalmente ocupadas pelos índios são constituídas por quatro aspectos constantes no $₫$ $1^{\circ}$ do Art. 231, como elementos constitutivos de uma terra tradicionalmente ocupada por índios, os quais devem ser considerados conjuntamente: a) as terras por eles habitadas em caráter permanente; b) as utilizadas para suas atividades produtivas; c) as imprescindíveis à preservação dos recursos ambientais necessários a seu bem-estar; d) as necessárias a sua reprodução física e cultural". E acrescenta que esses aspectos devem ser compreendidos "...segundo seus usos, costumes e tradiçôes."

O Jurista José Afonso da Silva (1993, p. 47) enfatiza que as terras tradicionalmente ocupadas não revelam uma relação temporal: “...terras que eles estariam ocupando desde épocas remotas que já se perderam na memória e, assim, somente estas seriam as terras deles. Não se trata, absolutamente, de posse ou prescrição imemorial, como se a ocupação indígena neste se legitimasse, e dela se originassem seus direitos sobre as terras, como uma forma de usucapiāo imemorial... O tradicionalmente refere-se não a uma circunstância temporal, mas ao modo tradicional de os índios ocuparem e utilizarem as terras e ao modo tradicional de produção, enfim, ao modo tradicional de como eles se relacionam com as terras."

Sobre a interpretação do que o constituinte quis referir quando garantiu aos índios o direito às terras tradicionalmente ocupadas, tem importante opiniāo o professor e jurista Dalmo de Abreu Dallari (1994, p. 110) quando substancia essa questão: “...qual o tempo que deve decorrer para que se possa dizer que existe uma tradiçáo? Aplicada aos costumes indígenas essa expressão, isso quer dizer muitos anos ou alguns anos são suficientes? As comunidades indígenas são sedentárias, são nômades, são habituadas a abandonar um território e depois voltar a ele? Qual o critério seguido pelos índios para contar o tempo? O índio está consciente da noção de tipo da sociedade não-índia e da importância dada ao tempo prolongado pelos aplicadores do direito dessa sociedade? O índio é capaz de simular um fato tradicional?". 
Ocorre, no entanto, que as terras hoje demarcadas ou em processo de demarcação para os Guarani, como vimos acima, são uma ínfima parcela daquilo que era o território tradicional desse povo. Mesmo sendo ínfimas parcelas de seu território tradicional que estão sendo requeridas por essa população, o reconhecimento e a regularização das terras vem sendo concretizados muito lentamente, porque encontram forte omissão do Órgão Indigenista Federal, inclusive a absoluta falta de recursos orçamentários e a incompreensão dos costumes Guarani, a pressão contrária de setores antiindígenas e a rejeição de ambientalistas que imaginam uma total destruição do ambiente reservado. Como vimos acima, a reprodução física e cultural Guarani só pode acontecer na relação com a Mata Atlântica. Ladeira (2001, p. 46) observa que no contexto das disputas territoriais o conceito de tradicionalidade como instrumento para embasar o fundamento jurídico deve ser entendido como uma categoria que legitima o direito e um atributo que define condição.

A legislação ambiental também avançou consideravelmente nos últimos anos. Além de um capítulo específico na CF de 1988 (Capítulo VI. Art. 225), certamente o maior avanço em termos de preservação encontra-se na ampla legislação ambientalista, especialmente nas Leis Federais e nas Resoluçóes do CONAMA - Conselho Nacional do Meio Ambiente. Mas, como citamos anteriormente, para alguns estudiosos do tema esses avanços refletem uma visão extremamente conservadora, e estão muito aquém dos debates mundiais.

O SNUC também não tem considerado a participação e contribuição indígena na preservação ambiental. Há inclusive uma visão equivocada a respeito das garantias legais, como o Art. 57 da Lei 9.985 ${ }^{14}$, de 18 de Julho de 2000, que regulamenta o art. 225, $\$ 1^{\circ}$, incisos I, II, III e VII da Constituição Federal que institui o Sistema Nacional de Unidades de Conservação da Natureza e dá outras providências:

\footnotetext{
${ }^{14}$ A Lei 9.985/2000 organiza as UC em duas categorias de conservação: Unidades de Proteção Integral e Unidade de Usos Sustentável. A diferença básica de ambas categorias é que a primeira admite apenas o uso indireto de seus recursos naturais. Estão relacionadas nessa categoria as Estações Ecológicas, as Reservas Biológicas, os Parques Nacionais, os Monumentos Naturais e os Refúgios da Vida Silvestre. Já na segunda categoria, que admite o uso sustentável de parcela de seus recursos naturais, estão relacionadas as seguintes categorias: Área de Proteção Ambiental, Ária de Relevante Interesse Ecológico, Floresta Nacional, Reserva Extrativista, Reserva de Fauna, Reserva de Desenvolvimento Sustentável e Reserva Particular do Patrimônio Natural.
} 
ART. 57. Os órgãos federais responsáveis pela execução das políticas ambiental e indigenista deverão instituir grupos de trabalho para, no prazo de cento e oitenta dias a partir da vigência desta Lei, propor diretrizes a serem adotadas com vistas à regularização das eventuais superposiçôes entre áreas indígenas e unidades de conservação.

Conforme argumenta Guimarães (2000, s/p), "as terras tradicionalmente ocupadas pelos índios são objeto de específico e preciso tratamento normativo no texto constitucional, enquanto as Unidades de Conservação resultam de normas infra-constitucionais, que por esta razão devem se submeter àquelas e não o contrário". Jamais uma Terra Indígena estará sobreposta a uma Unidade de Conservação, simplesmente porque a Terra Indígena é anterior a qualquer forma de ocupação e titulação.

Mesmo nas Unidades de Uso Sustentável, que de maneira geral são compatíveis com determinados usos de seus recursos ambientais, legalmente se tornam incompatíveis com a categoria de Terra Indígena, pois estas são de uso exclusivo das comunidades indígenas e, portanto, indisponíveis. O direito originário às terras tradicionalmente ocupadas pelas comunidades indígenas garante a esses povos o usufruto exclusivo. Assim sendo, na medida em que a terra indígena é reconhecida, todos os títulos incidentes serão nulos $\left(\$ 6^{\circ}\right.$ do Art. 231), sejam de particulares ou públicos. A UC jamais poderá ser criada quando incidir sobre terra indígenas, pelos mesmos motivos anteriormente expostos. Assim menciona Guimarães (2000, s/p): "além disso, se a Uniāo e somente o poder público federal considerar que uma área integrante dos limites de uma terra tradicionalmente ocupada por índios deva ser objeto de proteção ambiental, aplicando-se uma das Unidades de Conservação, tornarse-á necessário que esta possibilidade esteja prevista na lei complementar a que se refere o $\$ 6^{\circ}$ do art. 231 da CF, já que implicará na ocupação, pelo poder público de terras indígenas, sob pena de ser ato jurídico nulo e sem efeito jurídico."

\section{Necessidades de novos paradigmas ambientais}

A importância da biodiversidade da Mata Atlântica não poderá reduzirse a locais estratégicos de preservação. Ao mesmo tempo não poderá impor restriçóes a que os indígenas, seus habitante primeiros, sejam impedidos 
de habitar e usufruir, a seu modo, as florestas. O povo Guarani tem uma contribuição extremamente relevante no tocante à convivência com o meio ambiente justamente por compreendê-lo na sua complexidade. A organização social e econômica Guarani privilegia um sistema social sem exclusão. A reciprocidade em sua maior amplitude é a base das relaçóes sociais. Como vimos acima, a concepção ambiental Guarani está fundamentada na vivência do Tekoha, que produz e ao mesmo tempo distribui reciprocamente relaçóes de equilíbrio. Não pretendemos aqui exaltar a imagem do Guarani como o do "bom selvagem" perfeito, mas tentamos buscar compreender sua práxis cultural na relação com o meio ambiente que não é a práxis do ambientalismo moderno.

Certamente a abrangência do pensamento Guarani é ínfima no contexto brasileiro e menor ainda no contexto latino-americano, mas, como já assinalou Morin (2001, p. 101), “como sempre, a iniciativa só pode partir de uma minoria, a princípio incompreendida, às vezes perseguida. Depois, a idéia é disseminada e, quando se difunde, torna-se uma força atuante”.

As Unidades de Conservação são necessárias ao modelo de desenvolvimento que beneficia a busca individual do lucro e da acumulação sem limites, pois elas são partes constitutivas da destruição ambiental. Preservam-se determinadas glebas de terra, no geral as de menor interesse comercial e com considerável valor científico e cênico, e o restante é regulado minimamente para permitir a intensa exploração. Atualmente é comum grandes empresas, concentradoras de terra e renda, geradoras da exclusão social e por conseguinte danosas ao sistema completo ambiental e social, serem contempladas com premiaçóes por órgãos ambientais por manter uma pequena reserva de mata nativa em nascentes ou ciliares aos rios. Organizam minimamente algumas normas técnicas para alcançar o certificado de qualidade ISO 14001, externando uma imagem de preservadoras ambientais. Por outro lado, suas ações privam milhares de famílias do acesso à terra e dos bens produzidos.

A concepção e a prática ambiental do povo Guarani nos fazem pensar o cosmos complexo e completo, com todos seus elementos constitutivos. Para o Guarani preservar o meio ambiente não significa mata intocada, mas uso equilibrado. O manejo ambiental praticado pelas comunidades Guarani está muito longe de ser contemplado nas nossas legislaçôes. A contribuição de 
Morin (2001, p. 39-40) para esse entendimento é de extrema importância: "os novos conhecimentos, que nos levam a descobrir o lugar da Terra no cosmo, a Terra-sistema, a Terra-Gaia ou biosfera, a Terra pátria dos homens, não têm sentido algum enquanto isolados uns dos outros. A Terra não é a soma de um planeta físico, de uma biosfera e da humanidade. A Terra é a totalidade complexa físico-biológica-antropológica, onde a vida é uma emergência da história da Terra, e o homem, uma emergência da história da vida terrestre. A relaçáo do homem com a natureza não pode ser concebida de forma reducionista, nem de forma disjuntiva. A humanidade é uma entidade planetária e biosférica. O ser humano, ao mesmo tempo natural e supranatural, deve ser pesquisado na natureza viva e física, mas emerge e distingue-se dela pela cultura, pensamento e consciência. Tudo isso nos coloca diante do caráter duplo e complexo do que é humano: a humanidade não se reduz absolutamente à animalidade, mas, sem a animalidade, não há humanidade".

Nesse aspecto, entendemos que nossa contribuição para o debate não pode se limitar à quantidade de hectares de terras preservados, se o micoleão sobreviverá, se algumas espécies resistirão e se teremos ar e água para o futuro. Temos que pensar se todos teremos acesso à água e a todos os recursos naturais, no presente e no futuro. Se todos teremos acesso a alimentos saudáveis e conseguiremos conviver com as diferenças. De nada adiantará termos $10 \%$ do território preservado se alguns poucos se beneficiarão de toda riqueza produzida.

Diegues (1996, p. 21) sugere que "a conservação da diversidade biológica e a cultural devem caminhar juntas". Não podemos excluir o ser humano e as relaçóes produzidas do debate ambiental. Afinal somos parte do meio e por mais tecnologia que produzimos nada substituirá, e nada sobreviverá se não conseguirmos estabelecer novos paradigmas ambientais. Alguns oásis não darão conta de suprir a demanda de toda uma população. Pensar o meio ambiente requer uma visão interdisciplinar e, acima de tudo, uma abertura e postura clara; somos uma "comunidade de destino" (MORIN, 2001, p. 73), sujeitos a mesma ameaça, ao mesmo perigo ecológico da biosfera e do efeito estufa. 
Certamente a biodiversidade da Mata Atlântica tem recebido uma contribuição extremamente grande dos Guarani, e os Guarani com seus conhecimentos e sua cultura receberam uma importante contribuição do ecossistema da Mata Atlântica. Resta a nós, cidadãos planetários, também aprender com esse ecossistema e com esse povo indígena.

\section{Referências Bibliográficas}

ALMEIDA, Rubem Thomaz de. Laudo antropológico sobre a comunidade Guarani-Nandeva Oco'y/Jacutinga - PR. Rio de Janeiro: 1995, 165 p.

BRIGHENTI, Clovis Antonio. Integração e desintegração: análise do tratamento dispensado pelos estados Brasileiro e Argentino ao povo Guarani em Santa Catarina e na Província de Misiones. São Paulo, 2001. Dissertação (Mestrado em Integração da América Latina) - Programa de Pós Graduação em Integração na América Latina da Universidade de São Paulo - PROLAM/ USP, 2001, 216 p.

CARRASCO, Morita; BRIONES, Claudia. La tierra que nos quitaron. Buenos Aires: IWGIA, 1996, 296 p.

CLASTRES, Hélène. Terra sem mal. O profetismo tupi-guarani. São Paulo: Brasiliense, 1978, 123 p.

COMUNIDADES GUARANI DO LITORAL CATARINENSE. Guarani Hywy Rupã. Palhoça: 2004, 22 p.

DALLARI, Dalmo de Abreu. Argumento antropológico e linguagem jurídica. In: DALLARI, Dalmo de Abreu (Org.). A perícia antropológica em processos judiciais. Florianópolis: UFSC, 1994, p. 107-115.

DIEGUES, Antonio Carlos Santana. O mito moderno da natureza intocada. São Paulo: Hucitec, 1996, 169 p.

- A construção de uma nova ciência da conservaçáo para as áreas protegidas nos trópicos: a etno-conservação. Debate Sócio Ambiental, São Paulo, n. 13, ano V, p. 09-11, jul-out. 1999. 
DOOLEY, Robert. Vocabulário Guarani. Brasília: Summer Institute Linguistic, 1982, $322 \mathrm{p}$.

FOGEL, Ramón. Las raíces históricas. In: FOGEL, Ramón. Mbyá Recové. La resistencia de un pueblo indómito. Asunción: CERI, Universidad Nacional Pilar, 1998, p. 91-134.

GUIMARÃES, Paulo Machado. Proteção legal das terras indígenas. In: LARANJEIRA, Raimundo. Direito agrário brasileiro. São Paulo: LTR, 1999, p. 541-591.

- Superposição de unidades de conservação em terras tradicionalmente ocupadas por indio. Brasília: 2000, mimeo. 12 p.

LADEIRA, Maria Inês. O caminhar sob a luz. O território Mbya a beira do oceano. São Paulo, 1992. Dissertação (Mestrado) - Departamento de Antropologia da Pontifícia Universidade Católica de São Paulo PUC/SP, 1992, 192 p.

- Espaço geográfico Guarani-Mbya: significado, constituição e uso. São Paulo, 2001. Tese (Doutorado) - Programa de Pós-Graduação em Geografia Humana da Faculdade de Filosofia, Letras e Ciências Humanas da Universidade de São Paulo, 2001, 236 p.

MELIÀ, Bartomeu. A experiência religiosa Guarani. In: MARZAL, Manuel M. O rosto indio de Deus. Petrópolis: Vozes, 1989, p. 293-357.

MONTENEGRO, Raúl; FONTANA. José. Determinación del territorio que necesitan dos comunidades Mbyá Guarani para satisfacer sus necesidades vitales (zona del Moconá, Misiones), en función del impacto ambiental producido en la zona por empresas madereras y cazadores. Posadas: 2004, mimeo. 12 p.

MORIN, Edgar. A cabeça bem-feita: repensar a reforma, reformar o pensamento. Tradução Eloá Jacobina. 7. ed. Rio de Janeiro: Bertrand Brasil, 2001, 128 p.

NOELLI, Francisco Silva. Sem tekoha ao há tekó. Em busca de um modelo etnoarqueológico da aldeia e da subsistência Guarani e sua aplicação a uma área do Delta do Rio Jacui-RS. Porto Alegre, 1993. Dissertação (Mestrado em História) - Pontifícia Universidade Católica PUC/RS, 1993, 234 p.

ROCCO, Rogério. Legislaçâo Brasileira do Meio Ambiente. Rio de Janeiro: DP\&A, 2002, 283 p. 
SAGUIER, Rubén Barreiro. Literatura Guarani del Paraguay. Caracas/Venezuela: Biblioteca Ayacucho, 1980, 162 p.

SANTA CATARINA. Secretaria de Estado do Desenvolvimento Social Urbano e Meio Ambiente. Fundação do Meio Ambiente. SC Ambiental: Anuário 2004. Florianópolis, Imprensa Oficial do Estado, 2004, 50 p.

SCHADEN, Egon. A mitologia heróica de tribos indígenas do Brasil. Ensaio etnosociológico. Rio de Janeiro: MEC/Departamento de Imprensa Nacional, 1959.

- Aculturaçâo indígena. São Paulo: Biblioteca Pioneira de Ciências Sociais/Edusp, 1969.

. Aspectos fundamentais da cultura Guarani. 3. ed. São Paulo: EPU/ Edusp, 1974.

SILVA. José Afonso da. Terras tradicionalmente ocupadas pelos índios. In: SANTILLI, J. (Coord.). Os direitos indígenas e a Constituiçâo Federal. Porto Alegre: NDI, Sérgio Fabris, 1993, p. 45-50.

SUSNIK, Branislava. Dispersión tupi-guaraní prehistórica. Ensayo analítico. Asunción: Museo Etnografico Andres Barbero, 1975, 175 p.

- Los aborígenes del Paraguay. Etnohistória de los Guaranies. Época colonial. II. Asunción: Museo Etnografico Andres Barbero, 1979-1980, $333 \mathrm{p}$. 